\title{
Pentoxifylline Induces Lipolysis and Apoptosis of Human Preadipocytes, Keratinocytes and Fibroblasts In Vitro
}

\author{
II Kyu LeE ${ }^{1,3}$, Yun Jung $\mathrm{CHOI}^{1}$, Insop S $\mathrm{HI}^{2,3}$, Kyung-Soo KIM ${ }^{1,2,3}$, and Chang Jin $\mathrm{CHOI}^{1,3, *}$ \\ ${ }^{1}$ Department of Family Medicine, Seoul St. Mary's Hospital, ${ }^{2}$ Department of Integrative Medicine, \\ ${ }^{3}$ Research Center of Behavioral Medicine, The Catholic University of Korea, College of Medicine, Seoul 137-040, Republic of Korea
}

(Received September 25, 2009; Revised November 20, 2009; Accepted November 22, 2009)

\begin{abstract}
Pentoxifylline (PTX) has been used for the local reduction of fat tissue in the clinical setting. However, its safety and efficacy have not been proven. The aim of this study was to evaluate the effects of PTX on cell lines established from fat tissue. Newly cultured human preadipocytes and adipocytes from subcutaneous abdominal fat in addition to purchased human lung fibroblasts and keratinocytes were treated with PTX at different concentrations. Cell viability was determined using the Cell counting kit (CCK)- 8 assay and lipolysis was evaluated using an Elisa kit. DNA fragmentation, Western blot analysis, Hoechst and Propidium lodide $(\mathrm{PI})$ staining and fluorescence activated cell scanning analysis were performed to confirm apoptosis. The viability of adipocytes, preadipocytes, keratinocytes and fibroblasts was markedly decreased at concentrations of PTX above $20 \mathrm{mM}$. Apoptosis was induced at concentrations of PTX over $40 \mathrm{mM}$ in all cell lines. Lipolysis was increased by $60 \%$ at concentrations of PTX of $20 \mathrm{mM}$ compared to the control. In conclusion, the results of this study showed that $20 \mathrm{mM}$ of PTX induced lipolysis. At concentrations over 20 $\mathrm{mM}$, PTX reduced the viability of all cells studied including: adipocytes, preadipocytes, fibroblasts and keratinocytes, in a non-specific manner.
\end{abstract}

Keywords: Pentoxifylline, Apoptosis, Adipocyte, Preadipocyte, Fibroblast, Keratinocyte

\section{INTRODUCTION}

Adipose tissue mass is determined by competing processes regulating both the volume and number of adipocytes. With an increase in body weight, initially existing adipocytes become hypertrophied. As adipocytes exceed a critical cell size, the multipotent mesenchymal stem cells of adipose tissue are triggered to differentiate into mature adipocytes (Hauner et al., 1989; van Harmelen et al., 2003). The adipocyte size has been shown to correlate with the pattern of adipokine secretion; larger adipocytes have a more unfavorable profile of cytokine secretion than smaller adipocytes (Morin et al., 1998; Yang et al., 2004). Therefore, an optimal therapeutic approach to the treatment of obesity would regulate both the size and number of adipocytes.

Along with the growing national interest in obesity, a variety of treatment modalities have been developed; how-

${ }^{*}$ Corresponding author

Tel: +82-2-2258-1760 Fax: +82-2-2258-7795

E-mail: fmchcj@catholic.ac.kr ever, the safety and efficacy of most treatments have not been supported by scientific evidence. Mesotherapy, originally introduced in Europe, is a minimally invasive technique that consists of the intra- or subcutaneous injection of variable mixtures of natural plant extracts, homeopathic agents, pharmaceuticals, vitamins, and other bioactive substances (Accessed February 2nd, 2009). The use of mesotherapy in cosmetic medicine, to reduce and contour subcutaneous fat, is gaining popularity (Rotunda et al., 2005; Doerr, 2007), however, the safety and efficacy of this treatment has not been scientifically validated.

The compound 1-[5-oxohexyl]-3,7-dimethylxanthine (Pentoxifylline; PTX) is a common mesotherapy ingredient, used to increase blood circulation. As a non-specific phosphodiesterase (PDE)-inhibitor, PTX turns off tonic cyclic adenocine-3,5-monophophate (cAMP) hydrolysis, thereby contributing to a greater pool of CAMP and increased possible basal lipolysis (Snyder et al., 2005). Because of its hemorrhagic and anti-platelet properties, PTX has been used to treat peripheral vascular disease (Ward and Clissold, 1987; Moriau et al., 1995). PTX also has anti- 
oxidant activity as well as anti-TNF- $\alpha$ (Zabel et al., 1993) and anti-nuclear factor-kB (NF-kB) effects (Strieter et al., 1988). In a recent study carried out in a nonalcoholic steatohepatitis (NASH) mouse model, PTF administrated intra-abdominally significantly ameliorated NASH by inhibiting TNF- $\alpha$ and suppressing oxidative stress markers (Yalniz et al., 2007). Due to its anti-inflammatory, antioxidant and improved circulatory effects, PTF might improve the chronic inflammatory condition associated with obesity.

Adult human white adipose tissue has been reported to be composed of approximately $50-70 \%$ adipocytes, 20 $40 \%$ stromal vascular cells (i.e. preadipocytes, fibroblasts, multipotent mesenchymal cells), and $1-30 \%$ of infiltrated macrophages (Hauner, 2005). Therefore, the effects of PTX must be studied on other cell lines in addition to adipocytes. This is the first study to investigate the effects of PTX on human adipose tissue. The goal of this study was to investigate the effects of PTX on human adipocytes, preadipocytes, fibroblasts and keratinocytes in vitro to determine whether PTX induces lipolysis and apoptosis of adipocytes and preadipocytes, and determine whether PTX is specific for adipocytes and preadipocytes.

\section{MATERIALS AND METHODS}

\section{Specimens}

Adipose tissue samples were isolated from lipoaspirates obtained during elective liposuction surgery. Samples were collected from patients with no significant medical history and were not taking any medication. Approval for this study was obtained from the institutional review boards (IRB) of the Catholic University of Korea, College of Medicine and informed consent was obtained according to the Declaration of Helsinki.

\section{Isolation and culture of preadipocytes, keratinocytes and fibroblasts}

The preadipocytes were prepared by isolating them from lipoaspirates in the following manner: the lipoaspirates were washed three times with phosphate-buffered saline (PBS, Gibco-BRL, Grand Island, N.Y., USA) containing $10 \%$ antibiotic/antimycotic (P/S, Gibco-BRL) and the extracellular matrix was digested with $0.06 \%$ collagenase (collagenase type I, Invitrogen Corporation, Carlsbad, CA, USA) and 1\% bovine serum albumin (BSA, Bovogen, Ogilvie St. Essendon Vic, Australia). The above solution with the lipoaspirates were then placed in a shaking water bath for 2 hours at $37^{\circ} \mathrm{C}$, followed by filtration through a 40 $\mu \mathrm{M}$ nylon mesh (cell strainer, BD Falcon, Two oak park
Bedford MA, USA). Using erythrocyte lysis buffer (0.15 M ammonium chloride, $1.0 \mathrm{mM}$ potassium bicarbonate and $0.1 \mathrm{mM}$ EDTA), the erythrocytes were removed and the remaining cells were seeded in culture flasks while they were maintained under conditions identical to the conditions used for the preadipocytes. The cells were cultured in Minimum Essential Medium $\alpha$ ( $\alpha$-MEM, Gibco-BRL) supplemented with $10 \%$ Fetal bovine serum (FBS, Hyclone, Logan, Utah, USA) and 1\% Penicillin- Streptomycin (P/S, Gibco-BRL) and left in a humidified atmosphere containing $5 \% \mathrm{CO}_{2}$ at $37^{\circ} \mathrm{C}$. After 24 hours, the cultured cells were washed with PBS to remove non-adherent material. The medium was replaced twice a week during the third passage (P3). The keratinocyte and fibroblast cells were purchased from the American Type Culture Collection (ATCC, Manassas VA, USA). These cells were cultured in Dulbeco's modified Eagles 1s media (DMEM, Gibco-BRL) supplemented with 10\% FBS (Hyclone) and 1\% P/S (Gibco-BRL), and maintained in a humidified atmosphere containing $5 \% \mathrm{CO}_{2}$ at $37^{\circ} \mathrm{C}$.

\section{Cell survival assay}

Adipocytes: The preadipocytes were plated at 15,000 cells/well in 96-well plates and incubated for 24 hours. These cells were then treated with adipogenic media (DM-2/10, Zen-Bio, Inc., Research Triangle Park, Bovard, NC.,USA). After 14 days, the cells were further treated with $0,20,40,60,80$, and $100 \mathrm{mM}$ of PTX. After 24, 48, and 72 hours, the cells were treated with a $1 / 10$ volume of CCK-8 (Dojindo Molecular Technologies, Rockville, MD USA). After 2 hours of treatment with CCK-8, the cells were assessed for viability using an ELISA reader.

\section{Other cells}

Starvation: The preadipocytes, fibroblasts and keratinocytes were seeded $1.5 \times 10^{4}$ cells/well in 96-well plates. After 24 hours, the cells were exchanged with $10 \%$ FBS media. After 3 days, these cells were treated with $0,20,40$, 60,80 , and $100 \mathrm{mM}$ of PTX. After 24,48 , and 72 hours, the cells were assessed for viability using an ELISA reader as described for the adipocytes.

Without starvation: The preadipocytes, fibroblasts and keratinocytes were seeded $5 \times 10^{4}$ cells/well in 96-well plates. After 24 hours, these cells were treated with 0,20 , $40,60,80$, and $100 \mathrm{mM}$ of PTX. After 24, 48, and 72 hours, they were assessed for viability using an ELISA reader as described for the adipocytes.

\section{Lipolysis assay}

The preadipocytes from the third passage were plated 
onto 96 well plates with $5 \times 10^{4}$ cells/well and cultured for 24 hours in control medium (DMEM with 10\% FBS and 1\% antibiotic/antimycotic at 37 and $5 \% \mathrm{CO}_{2}$ ); then the medium was replaced with adipogenic medium (DM-2/10, Zen-Bio, Inc., Research Triangle Park, Bovard, NC.,USA). The culture medium was changed every 3 days and cultured for 2 weeks.

After treatment with different concentrations of pentoxifylline $(0,2 \mathrm{nM}, 20 \mathrm{nM}, 200 \mathrm{nM}, 2 \mathrm{mcM}, 2 \mathrm{mM}, 20 \mathrm{mM})$ added to the culture medium, newly differentiated adipocytes were analyzed by a lipolysis assay according to the method of Brasaemle (Brasaemle, Dolios et al., 2004).

\section{DNA fragmentation}

The preadipocytes, fibroblasts and keratinocytes were plated at $9 \times 10^{5}$ cells/ well in $60 \mathrm{~mm}$ dishes and incubated for 24 hours. The cells were treated with 0, 20, 40, 60, 80, and $100 \mathrm{mM}$ of PTX. After 24 hours, DNA was extracted using the Qiagen mini kit (Qiagen; Max-Volmer-Strabe, Hilden, Germany). Electrophoresis (using $1 \%$ agarose gel with ethidium bromide) of $5 \mu \mathrm{g}$ of DNA from each cell line was separated for further analysis. The changes were evaluated under a UV detector.

\section{Nuclear condensation:}

The preadipocytes, fibroblasts and keratinocytes were plated at $9 \times 10^{5}$ cells/ well in $60 \mathrm{~mm}$ dishes and incubated for 24 hours. The cells were treated with 0,20 , and $40 \mathrm{mM}$ of PTX for 24 hours. Then $3.7 \%$ formaline was added for 10 minutes and 4',6- Diamidino-2-phenylindole, dihydrochloride (Sigma) and Propidium lodide (PI) was added at 5 ug/well. The nuclei were stained with Hoechst 33258 and the changes of the nuclei were evaluated under a florescent microscope.

\section{Western blot analysis}

Antibodies for Bcl-2, Bax, Caspase 3 and GAPDH were purchased from R\&D Systems (R\&D Systems, Minneapolis, MN., USA). The preadipocytes, fibroblasts and keratinocytes were plated at $9 \times 10^{5}$ cells/ well in $60 \mathrm{~mm}$ dishes and incubated for 24 hours. The cells were treated with 0 , $20,40,60,80$, and $100 \mathrm{mM}$ of PTX. After 24 hours, the cells were lysed in RIPA-B buffer $(0.5 \%$ Nonidet P-40, 20 $\mathrm{mM}$ Tris, pH 8.0, $50 \mathrm{mM} \mathrm{NaCl}, 50 \mathrm{mM} \mathrm{NaF}, 100 \mathrm{IM}$ Na3VO4, $1 \mathrm{mM} \mathrm{DTT}$, and $50 \mathrm{lg} / \mathrm{ml}$ PMSF) for 1 hour on ice. The insoluble materials were removed by centrifugation at $12,000 \mathrm{rpm}$ for $20 \mathrm{~min}$ at $4^{\circ} \mathrm{C}$. The supernatant was then directly subjected to sodium dodecyl sulfate polyacrylamide gel electrophoresis (SDS- PAGE). The proteins were transferred to a nitrocellulose membrane. The blots were blocked in phosphate-buffered saline containing $5 \%$ skim milk and $0.05 \%$ Tween 20 . This was followed by incubation with the primary and HRP-conjugated secondary antibodies. Detection was performed according to the enhanced chemiluminescence protocol (Amersham, Arlington, Heights, IL., USA).

\section{Statistical analysis}

Cell viabilities and lipolysis were expressed as mean \pm standard deviation. The significance level of treatment effects was determined using one way analysis of variance (ANOVA) followed by Tukey's post- hoc analysis and $p$-values lower than 0.05 was considered statistically significancy.

\section{RESULTS}

The culture of isolated preadipocytes reached confluence on day 3 . Adding adipogenic differentiation medium resulted in the preadipocyte cells increasing in size, becoming rounder and the presence of intracellular lipid droplets in the cytoplasm. The cell population on day 14 was approximately $50 \%$ adipocytes containing small lipid droplets; the adipocytes were stained with oil red-O on day 21. The $\mathrm{pH}$ of the culture medium ranged from 6.7 at 20 $\mathrm{mM}$ of PTX to 7.1 at $80 \mathrm{mM}$ PTX (Table I).

\section{Effect of PTX on cell viability}

After 24 hours of incubation with PTX, adipocyte viability was decreased by $58.3 \%$ at $20 \mathrm{mM}$ and a similarly reduced viability was detected above $40 \mathrm{mM}$ of PTX (Fig. 1A). After 48 and 72 hours of incubation, the adipocyte viability showed similar results. The viability of preadipocytes, keratinocytes and fibroblasts decreased significantly at concentrations of PTX above $20 \mathrm{mM}$ (Fig. 1B-D respectively). The cell viability was decreased more with starvation than with $10 \%$ FBS added to all three cell lines.

\section{Effect of PTX at lower concentrations on adipocyte viability and lipolysis}

Adipocyte viability was slightly decreased, by $20 \%$, with $2 \mathrm{mM}$ of PTX (Fig. 2A). From $2 \mathrm{nM}$ to $2 \mathrm{mM}$ of PTX, lipolysis increased by $10 \%$ compared to the control, and it increased by $60 \%$ at $20 \mathrm{mM}$ of PTX (Fig. 2B).

Table I. pH changes of dissolved media according to various pentoxifylline (PTX) concentration

\begin{tabular}{lcccccc}
\hline Concentration $(\mathrm{mM})$ & 0 & 20 & 40 & 60 & 80 & 100 \\
$\mathrm{p} \mathrm{H}$ & 6.8 & 6.7 & 6.9 & 7.0 & 7.1 & 7.0 \\
\hline
\end{tabular}



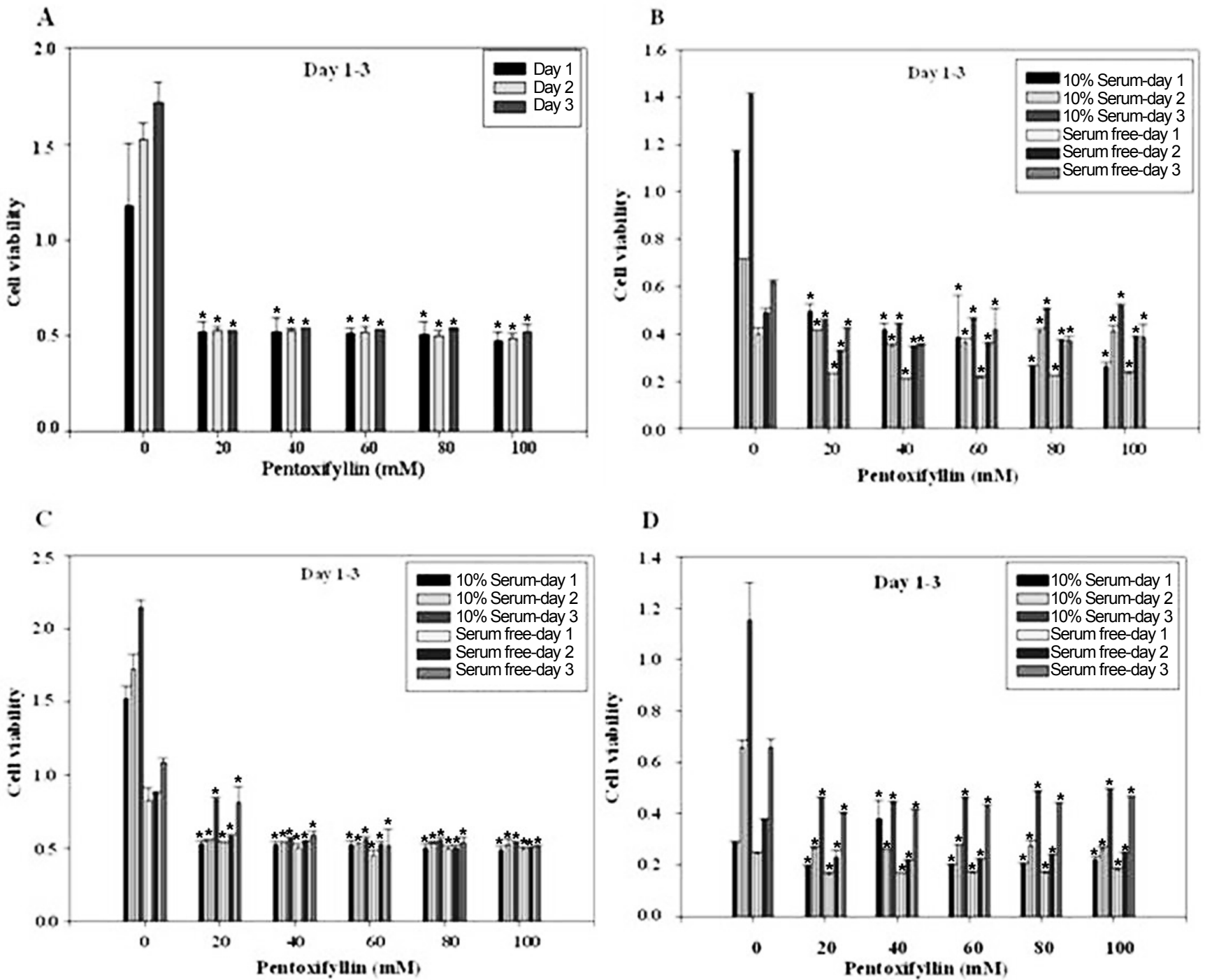

Fig. 1. The effect of pentoxifylline (PTX) on human adipocyte (A), human preadipocyte (B), human keratinocyte (C) and human lung fibroblast (D) cell viability. After 24 hours of incubation with PTX, adipocyte viability was decreased significantly at concentrations above $20 \mathrm{mM} \mathrm{PTX}$. The viability of preadipocyte, fibroblast and keratinocyte cells was decreased at concentrations above $20 \mathrm{mM}$ in both the starvation and $10 \%$ FBS groups. The numbers in the left column represent relative viability. The standard deviations are shown on top of each bar. These experiments were performed at least three times in duplicate. * $p<0.05$ by Tukey's post-hoc analysis.

\section{Effect of PTX on preadipocyte, keratinocyte and fibroblast cell Apoptosis}

DNA fragmentation was not observed in the control samples and at $20 \mathrm{mM}$ of PTX; however, it was detected above $40 \mathrm{mM}$ of PTX (Fig. 3). Nuclear condensation was observed at $20 \mathrm{mM}$ of PTX and complete condensation was observed at $40 \mathrm{mM}$ of PTX (Fig. 4). The expression of $\mathrm{Bcl}-2$, did not differ at different concentrations of PTX in the preadipocyte, fibroblast and keratinocyte cells; however, the expression of Bax and Caspase-3 showed a dose-response correlation in up to $60 \mathrm{mM}$ of PTX. Above $60 \mathrm{mM}$ of PTX, the expression of Bax and Caspase-3 decreased
(Fig. 5).

\section{DISCUSSION}

Recent studies have consistently shown hypoxic responses of adipose tissue (Kabon et al., 2004; Fleischmann et al., 2005; Rausch et al., 2008). This finding has suggested that cellular metabolism is associated with obesity (Hosogai et al., 2007; Ye, 2009). In obese individuals, the adipose tissue blood flow rate has been shown to be $30-40 \%$ lower than in non-obese subjects (Bolinder et al., 2000). 


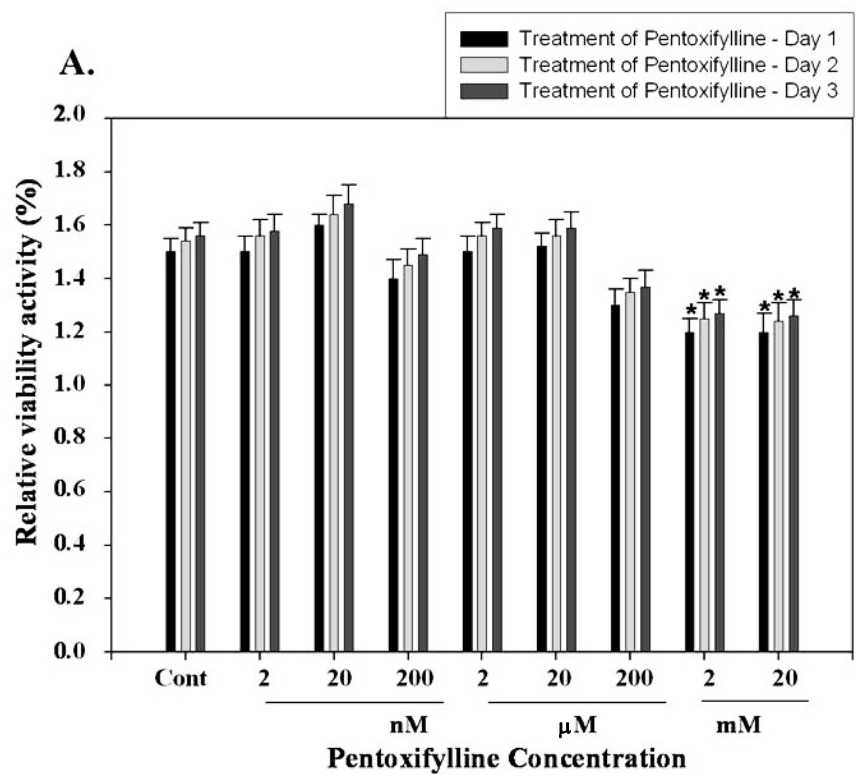

B.

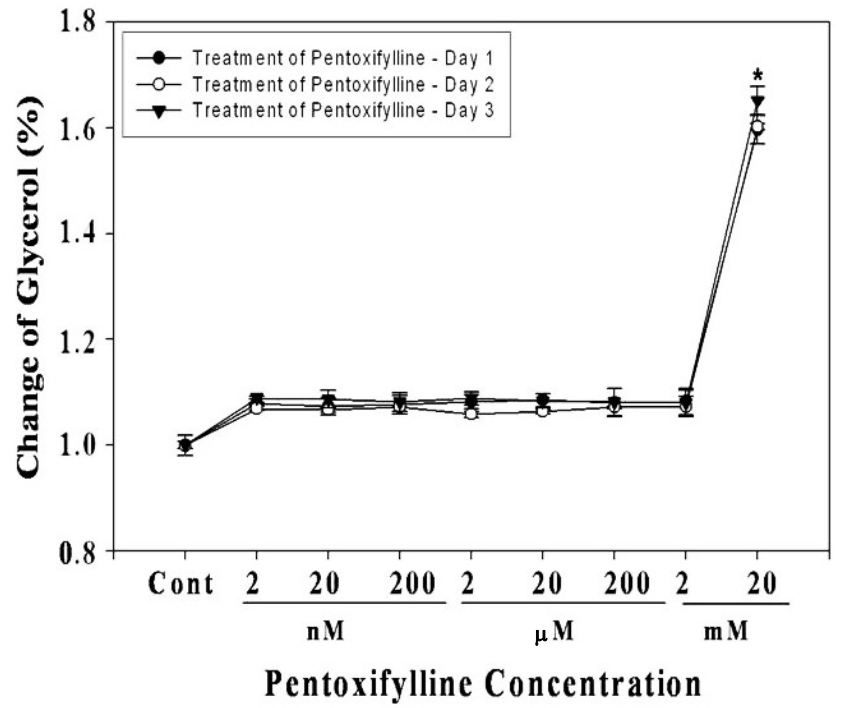

Fig. 2. The effect of pentoxifylline (PTX) at lower concentration on human adipocyte viability (A) and lipolysis (B). Adipocyte viability was slightly decreased above $2 \mathrm{mM}$ of PTX. Lipolysis was increased by $10 \%$ at concentrations from $2 \mathrm{nM}$ to $2 \mathrm{mM}$ of PTX and by $60 \%$ at a concentration of $20 \mathrm{mM}$ of PTX. The numbers in the left column represent relative viability and change of the glycerol level. The standard deviations are shown on the top of each bar. These experiments were performed at least three times in duplicate. ${ }^{*} p<0.05$ by Tukey's post-hoc analysis.

Preadipocyte
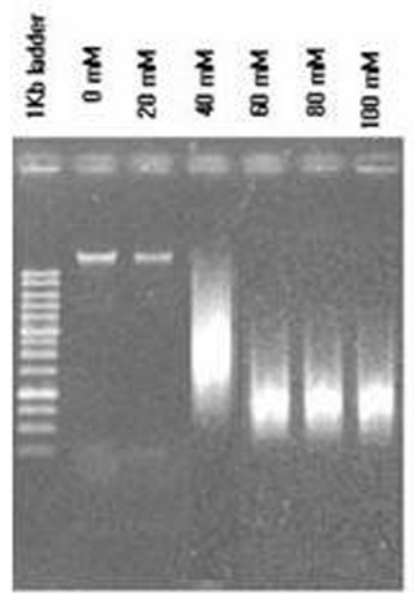

Keratinocyte
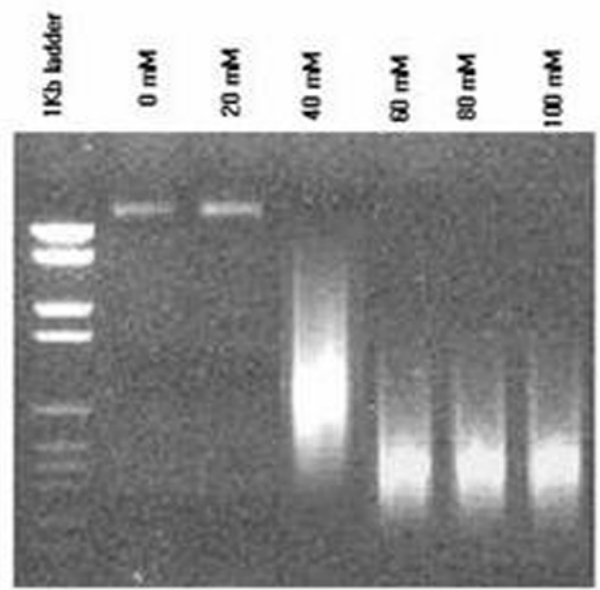

Fibroblast
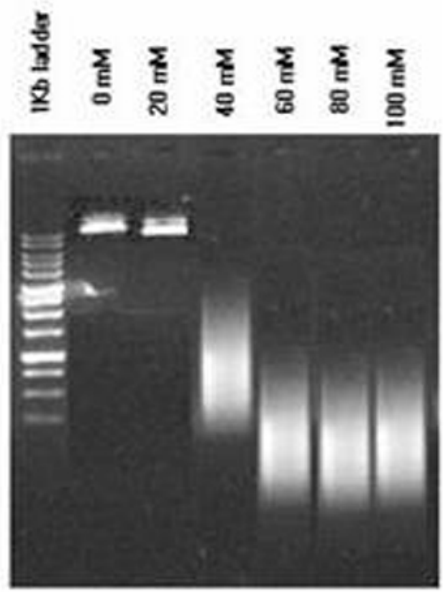

Fig. 3. The effect of pentoxifylline (PTX) on the DNA fragmentation of each cell line. DNA fragmentation was not observed in the controls and at $20 \mathrm{mM}$ of PTX; it was detected above $40 \mathrm{mM}$ of PTX. DNA was extracted from each of the cell lines and gel electrophoresis performed after the indicated treatment concentrations of PTX for 24 hours. Lane 1 (M): 1 Kb size marker, Lane 2 through 7: treatment of $0,20,40,60,80$, and $100 \mathrm{mM}$ concentration of PTX.

PTX improves the circulation, primarily by increasing red blood cell deformability, by reducing blood viscosity and by decreasing the potential for platelet aggregation and thrombus formation (Ward and Clissold, 1987; Moriau et al., 1995). PTF also inhibits proinflammatory cytokines. PTX blocks NF-kB activation and suppresses NF-KB dependent synthesis and the release of TNF- $\alpha$ (Strieter et al., 1988; Zabel et al., 1993). Therefore, PTX may serve as a 

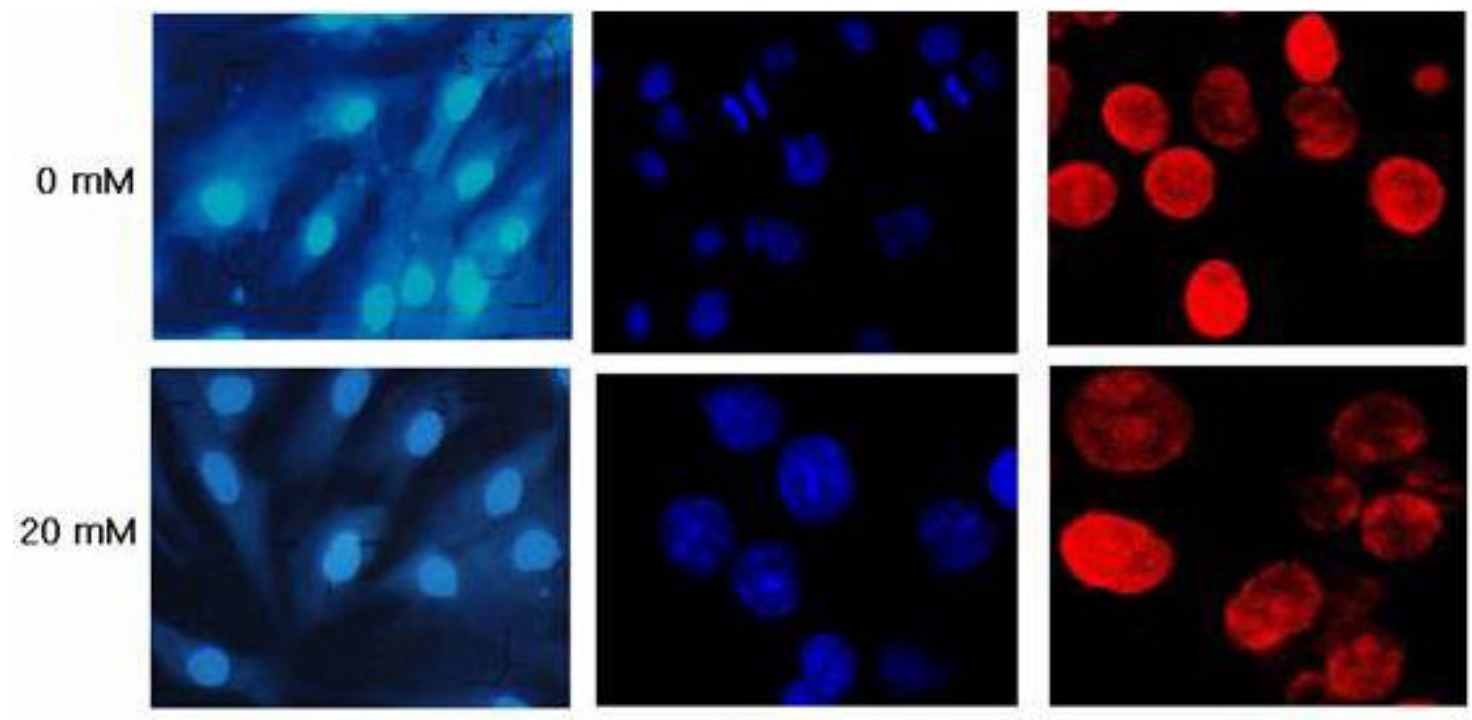

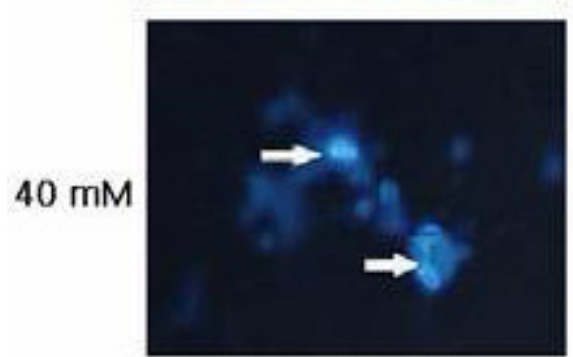

Preadipocyte

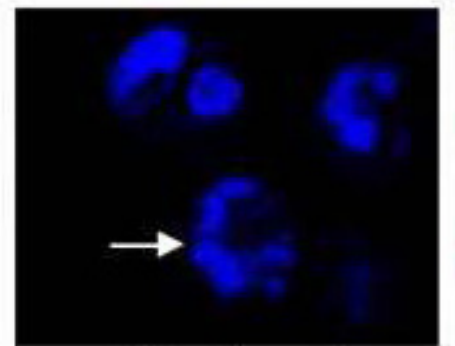

Keratinocyte

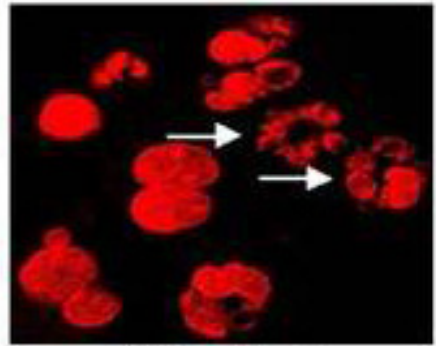

Fibroblast

Fig. 4. The effect of pentoxifylline (PTX) on nuclear condensation for each cell line. The cells were treated with the indicated concentration of PTX for 24 hours. Then, 3.7\% formaline was added for 10 minutes and 4',6-Diamidino-2-phenylindole, dihydrochloride and Propidium lodide (PI) injected at a dose of $5 \mu \mathrm{g} /$ well. The nuclei were stained with Hoechst 33258 and the changes in the nuclei were evaluated under a florescent microscope. DNA is shown in the blue and red colors. Nuclear condensation was detected at concentrations above $20 \mathrm{mM}$ PTX and complete condensation was observed at $40 \mathrm{mM}$ of PTX.

potential adjunct therapeutic agent for the treatment of conditions where TNF- $\alpha$ production plays a significant role. PTX has been reported to be a possible agent for the treatment of steatohepatitis (Yalniz et al., 2007), sepsis (Selim et al., 2004), kidney disease (Ducloux et al., 2001), as well as cancer (Rauko P et al., 1998; Rishi et al., 2009). In the NASH animal model, PTX significantly ameliorated the histopathological lesions associated with NASH and decreased the aminotransferase levels by its antioxidative and anti-TNF- $\alpha$ effects (Yalniz et al., 2007). Prior to these findings, the only clinically confirmed treatment of $\mathrm{NASH}$ was weight reduction (Moschen and Tilg, 2008).

Fat dissolving local injections have two therapeutic effects; First, the injected reagents are toxic to adipose and other associated cells, causing permanent removal of fat tissue; second, the injections have been associated with a temporary decrease in the fat stores, resulting in smaller fat cells (Rotunda et al., 2005). The results of this study showed that the effects of PTX on adipocyte cells differed according to the PTX concentration. PTX concentrations above $20 \mathrm{mM}$ reduced adipocyte viability; at lower concentrations (2 $\mathrm{nM}-20 \mathrm{mM})$, PTX induced lipolysis, which was $60 \%$ at $20 \mathrm{mM}$ concentrations. The effects of PTX on preadipocyte, fibroblast and keratinocyte cells were similar, above $20 \mathrm{mM}$ of PTX; the viability of all three cell lines was decreased and the expression of Bax and Caspase-3 showed a dose-response correlation in up to $60 \mathrm{mM}$ of PTX. Even though there is no comparable report of PTX induced apoptosis, decreased expression of of Bax and Caspase- 3 above $60 \mathrm{mM}$ of PTX might be explained by posttranslational proteins degradation at high concentration of PTX.

Therefore, the effects of PTX above $20 \mathrm{mM}$ were not cell specific. Previous studies have reported that $20 \mathrm{mM}$ PTX was the minimum concentration necessary to produce a reproducible and reliable down-regulation of TNF- $\alpha$ in lip- 


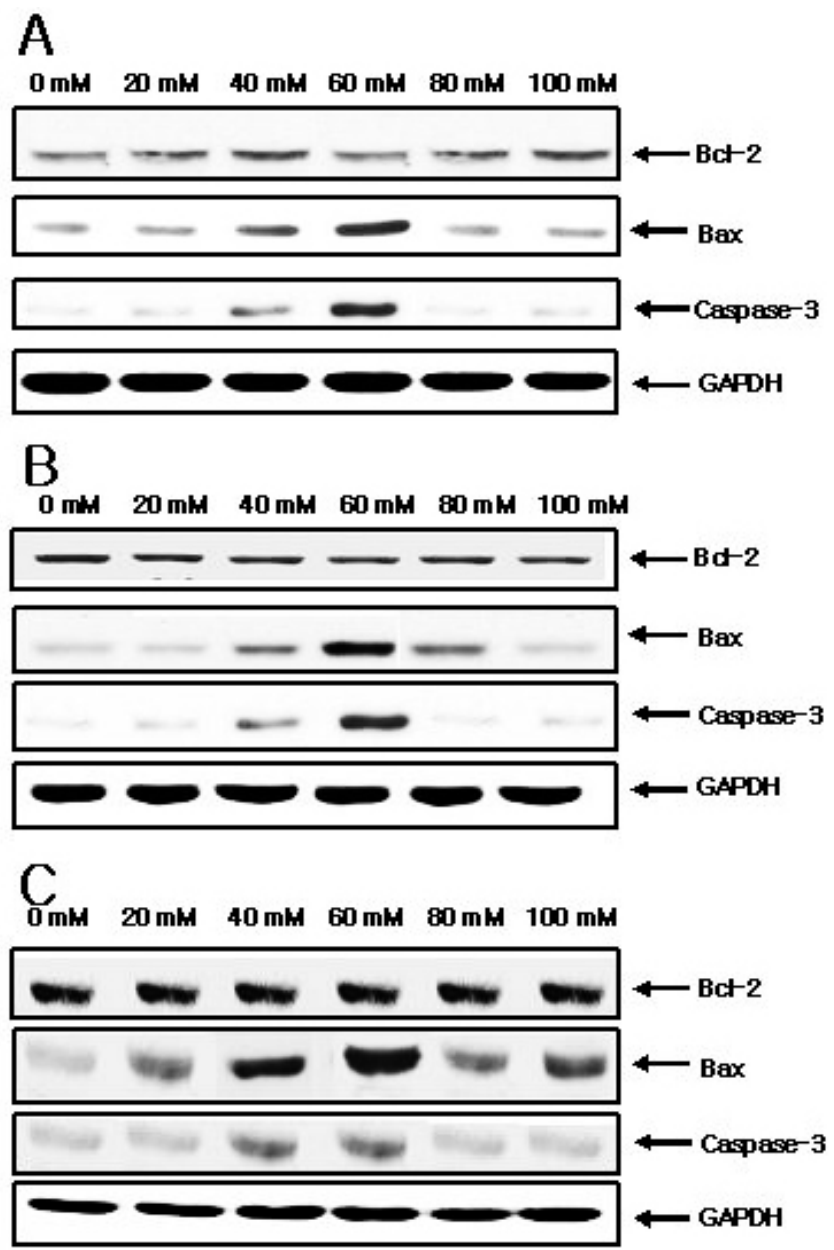

Fig. 5. The effect of pentoxifylline (PTX) on Bcl-2, Bax, and Caspase-3 expression in preadipocyte $(A)$, keratinocyte $(B)$ and fibroblast (C) cells. The cells were treated with $0,20,40,60,80$, and $100 \mathrm{mM}$ of PTX for 24 hours and were lysed in RIPA-B buffer (0.5\% Nonidet P-40, $20 \mathrm{mM}$ Tris, $\mathrm{pH} 8.0,50 \mathrm{mM} \mathrm{NaCl}, 50$ $\mathrm{mM} \mathrm{NaF}, 100 \mathrm{IM} \mathrm{Na} 3 \mathrm{VO} 4,1 \mathrm{mM}$ DTT, and $50 \mathrm{lg} / \mathrm{ml} \mathrm{PMSF}$ ) for 1 hour. The supernatant was subjected to SDS-PAGE. The blots were blocked in phosphate-buffered saline containing 5\% skim milk and $0.05 \%$ Tween 20 , followed by incubation with the primary and HRP-conjugated secondary antibodies. Detection was performed according to the enhanced chemiluminescence protocol. The expression of $\mathrm{Bcl}-2$ did not differ at different concentrations of PTX; however, the expression of Bax and Caspase- 3 had a dose-response correlation up to $60 \mathrm{mM}$ of PTX. The expression of Bax and Caspase- 3 was decreased at concentrations above $60 \mathrm{mM}$ PTX.

opolysaccharide stimulated peripheral blood mononuclear cells (Coimbra et al., 2005; Deree et al., 2008). The currently available PTX concentration in Korea is $73 \mathrm{mM}$. However, there are a variety of different formulas used for mesotherapy. Therefore, although we investigated a wide range of PTX concentrations, we do not know if the doses studied correspond to those used clinically for any given patient.

The results of our study showed that PTX below $20 \mathrm{mM}$ induced lypolysis in adipocytes; there are several possible underlying mechanisms that might explain this. As a non specific phosphodiesterase inhibitor, PTX turns off tonic cAMP hydrolysis, contributing to a greater pool of cAMP and increased possible basal lipolysis (Schandené $L$ et al., 1992). Another possibility is related to the findings that TNF- $\alpha$ increases the rate of lipolysis in humans in vivo (Starnes et al., 1988) and in primary cultures of newly differentiated human preadipocytes (Hauner et al., 1995). If PTX below 20 mM cannot block TNF- $\alpha$ completely, TNF- $\alpha$ might induce lypolysis.

The effects of PTX induced non specific apoptosis in all three cell lines studied; this result could be explained by the following. PTX has been reported as a potential chemotherapeutic agent. NF- $\mathrm{KB}$ regulates the expression of many genes that are critical for apoptosis (Rishi et al., 2009). In addition, PTX might be associated with nonspecific cell stress that leads to apoptosis. However, it is unclear how TNF- $\alpha$ would cause apoptosis. Prins et al. found that $425 \mathrm{ng} / \mathrm{ml}$ of TNF- $\alpha$ induced apoptosis of human white adipocyte cells in vitro (Prins et al., 1994). Because this level of TNF is too high to be considered within the normal physiologic range, it may have relevance only for extreme conditions such as cachexia or sepsis (Qian et al., 2001).

In conclusion, the results of this study showed that PTX at $20 \mathrm{mM}$ induced lipolysis and that concentrations above this level reduced the cell viability of adipocytes, preadipocytes, fibroblasts, and keratinocytes in a non specific manner. Further studies including in vivo studies are now needed to further explore the effects of PTX.

\section{ACKNOWLEDGMENTS}

The authors thank other members of our laboratory for their valuable assistance. This study was supported by the Korean Academy Family Medicine and a grant from the Korea Health $21 \mathrm{R} \& \mathrm{D}$ Project, Ministry of Health and Welfare, Republic of Korea (Project No. A060093) and the Korean Society for the Study of Obesity.

\section{REFERENCES}

Bolinder, J., Kerckhoffs, D. A., Moberg, E., Hagström-Toft, E. and Arner, P. (2000). Rates of skeletal muscle and adipose tissue glycerol release in nonobese and obese subjects. Diabetes. 49, 797-802.

Brasaemle, D. L., Dolios, G., Shapiro, L. and Wang, R. (2004). 
Proteomic analysis of proteins associated with lipid droplets of basal and lypolytically stimulated 3T3-L1 adipocytes. J. Biol. Chem. 279, 46835-46842.

Coimbra, R., Melbostad, H., Loomis, W., Tobar, M. and Hoyt, D. B. (2005). Phosphodiesterase inhibition decreases nuclear factor-kappaB activation and shifts the cytokine response toward anti-inflammatory activity in acute endotoxemia. $\mathrm{J}$. Trauma 59, 575-582.

Deree, J., Martins, J. O., Melbostad, H., Loomis, W. H. and Coimbra, R. (2008). Insights into the regulation of TNF-alpha production in human mononuclear cells: the effects of non-specific phosphodiesterase inhibition. Clinics (Sao Paulo) $63,321-328$.

Doerr, T. D. (2007). Lipoplasty of the face and neck. Curr. Opin. Otolaryngol. Head Neck Surg. 15, 228-232.

Ducloux, D., Bresson-Vautrin, C. and Chalopin J. (2001). Use of pentoxifylline in membranous nephropathy. Lancet 357, 1672-1673.

Fleischmann, E., Kurz, A., Niedermayr, M., Schebesta, K., Kimberger, O., Sessler, D. I., Kabon, B. and Prager, G. (2005). Tissue oxygenation in obese and non-obese patients during laparoscopy. Obes. Surg. 15, 813-819.

Hauner, H. (2005). Secretory factors from human adipose tissue and their functional role. Proc. Nutr. Soc. 64, 163-169.

Hauner, H., Entenmann, G., Wabitsch, M., Gaillard, D., Ailhaud, G., Negrel, R. and Pfeiffer E. F. (1989). Promoting effect of glucocorticoids on the differentiation of human adipocyte precursor cells cultured in a chemically defined medium. $J$. Clin Invest. 84, 1663-1670.

Hauner, H., Petruschke, T., Russ, M., Röhrig, K. and Eckel, J. (1995). Effects of tumour necrosis factor alpha (TNF alpha) on glucose transport and lipid metabolism of newly-differentiated human fat cells in cell culture. Diabetologia. $\mathbf{3 8}$ 764-771.

Hosogai, N., Fukuhara, A., Oshima, K., Miyata, Y., Tanaka, S. Segawa, K., Furukawa, S., Tochino, Y., Komuro, R., Matsuda, M. and Shimomura, I. (2007). Adipose tissue hypoxia in obesity and its impact on adipocytokine dysregulation. Diabetes. 56, 901-911.

Kabon, B., Nagele, A., Reddy, D., Eagon, C., Fleshman, J. W., Sessler, D. I. and Kurz, A. (2004). Obesity decreases perioperative tissue oxygenation. Anesthesiology 100, 274280.

Moriau, M., Lavenne-Pardonge, E., Crasborn, L., von Frenckell, R. and Col-Debeys, C. (1995). The treatment of severe or recurrent deep venous thrombosis. Beneficial effect of the co-administration of antiplatelet agents with or without rheological effects, and anticoagulants. Thromb. Res. 78, 469-482.

Morin, C. L., Gayles, E. C., Podolin, D. A., Wei, Y., Xu, M. and Pagliassotti, M. J. (1998). Adipose tissue-derived tumor necrosis factor activity correlates with fat cell size but not insulin action in aging rats. Endocrinology 139, 4998-5005.

Moschen, A. R. and Tilg, H. (2008). Nutrition in pathophysiology and treatment of nonalcoholic fatty liver disease. Curr. Opin. Clin. Nutr. Metab. Care 11, 620-625.

Prins, J. B., Walker, N. I., Winterford, C. M. and Cameron, D. P. (1994). Human adipocyte apoptosis occurs in malignancy. Biochem. Biophys. Res. Commun. 205, 625-630.

Qian, H., Hausman, D. B., Compton, M. M., Martin, R. J.,
Della-Fera, M. A., Hartzell, D. L. and Baile, C. A. (2001) TNFalpha induces and insulin inhibits caspase 3-dependent adipocyte apoptosis. Biochem. Biophys. Res. Commun. 284, 1176-1183.

Rauko, P., Sedlák, J., Duraj, J., Szekeres, M. F. and Novotný, L. (1998). Pentoxifylline stimulates drug-induced apoptosis in leukemic cells. Neoplasma 45, 296-300.

Rausch, M. E., Weisberg, S., Vardhana, P. and Tortoriello, D. V. (2008). Obesity in C57BL/6J mice is characterized by adipose tissue hypoxia and cytotoxic T-cell infiltration. Int. J. Obes. (Lond.) 32, 451-463.

Rishi, L., Gahlot, S., Kathania, M. and Majumdar, S. (2009). Pentoxifylline induces apoptosis in vitro in cutaneous $\mathrm{T}$ cell lymphoma (HuT-78) and enhances FasL mediated killing by upregulating Fas expression. Biochem. Pharmacol. 77, 3045.

Rotunda, A. M., Avram, M. M. and Avram, A. S. (2005). Cellulite: Is there a role for injectables? Int. J. Obes. (Lond.) 32, 451463.

Schandené, L., Vandenbussche, P., Crusiaux, A., Alègre, M. L. Abramowicz, D., Dupont, E., Content, J. and Goldman, M. (1992). Differential effects of pentoxifylline on the production of tumour necrosis factor-alpha (TNF-alpha) and interleukin6 (IL-6) by monocytes and T cells. Immunology 76, 30-34.

Selim, K., Hüseyin, C., Ibrahim, K. H., Hasan, B. U., Kazim, U. and Hüseyin, K. (2004). Effect of pentoxifylline on tumor necrosis factor-alpha and interleukin-6 levels in neonatal sepsis. Med. J. Malaysia 59, 391-394.

Snyder, P. B., Esselstyn, J. M., Loughney, K., Wolda, S. L. and Florio, V. A. (2005). The role of cyclic nucleotide phosphodiesterases in the regulation of adipocyte lipolysis. J. Lipid Res. 46, 494-503.

Starnes, H. F. Jr., Warren, R. S., Jeevanandam, M., Gabrilove J. L., Larchian, W., Oettgen, H. F. and Brennan, M. F. (1988). Tumor necrosis factor and the acute metabolic response to tissue injury in man. J. Clin. Invest. 82, 13211325.

Strieter, R. M., Remick, D. G., Ward, P. A., Spengler, R. N., Lynch, J. P. 3rd., Larrick, J. and Kunkel, S. L. (1988). Cellular and molecular regulation of tumor necrosis factor-alpha production by pentoxifylline. Biochem. Biophys. Res. Commun. 155, 1230-1236.

van Harmelen, V., Skurk, T., Röhrig, K., Lee, Y. M., Halbleib, M., Aprath-Husmann, I. and Hauner, H. (2003). Effect of BMI and age on adipose tissue cellularity and differentiation capacity in women. Int. J. Obes. Relat. Metab. Disord. 27, 889- 895.

Ward, A. and Clissold, S. P. (1987). A review of its pharmacodynamic and pharmacokinetic properties, and its therapeutic efficacy. Drugs 34, 50-97.

Wikimedia Foundation, Inc: Mesotherapy [internet] Wikimedia Foundation; c2001-2009. [cited 2009 Feb 2]. Available from: http://en.wikipedia.org/wiki/Mesotherapy.

Yalniz, M., Bahçecioğlu, I. H., Kuzu, N., Celebi, S., Ataseven, H., Ustündağ, B., Ozercan, I. H. and Sahin, K. (2007). Amelioration of steatohepatitis with pentoxifylline in a novel nonalcoholic steatohepatitis model induced by high-fat diet. Dig. Dis. Sci. 52, 2380-2386.

Yang, X., Jansson, P. A., Nagaev, I., Jack, M. M., Carvalho, E., Sunnerhagen, K. S., Cam, M. C., Cushman, S. W. and Smith, U. (2004). Evidence of impaired adipogenesis in in- 
sulin resistance. Biochemical and biophysical research communications. Biochem. Biophys. Res. Commun. 317, 10451051.

Ye, J. (2009). Emerging role of adipose tissue hypoxia in obesity and insulin resistance. Int. J. Obes. (Lond.) 33,
54-66.

Zabel, P., Schade, F. U. and Schlaak, M. (1993). Inhibition of endogenous TNF formation by pentoxifylline. Immunobiology 187, 447-463. 